\title{
Exposure to purified lignan from flaxseed (Linum usitatissimum) alters bone development in female rats
}

\author{
Wendy E. Ward ${ }^{1}$, Yvonne V. Yuan ${ }^{2}$, Angela M. Cheung ${ }^{3}$ and Lilian U. Thompson ${ }^{1 *}$ \\ ${ }^{1}$ Department of Nutritional Sciences, University of Toronto, Toronto, Ontario M5S 3E2, Canada \\ ${ }^{2}$ School of Nutrition, Ryerson Polytechnic University, Toronto, Ontario M5B 2K3, Canada \\ ${ }^{3}$ Osteoporosis Program, Department of Medicine, University Health Network \& Mount Sinai Hospital, Toronto, Ontario, \\ M5G 2C4, Canada
}

(Received 11 October 2000 - Revised 26 April 2001 - Accepted 7 June 2001)

\begin{abstract}
Due to the potential oestrogenic effects of secoisolariciresinol diglycoside (SDG), the mammalian lignan precursor in flaxseed (Linum usitatissimum), we hypothesized that exposure to purified SDG during early life would have a positive effect on developing bone. This present study determined whether exposure to SDG purified from flaxseed during suckling via mother's milk or continuously to adolescence (postnatal day (PND) 50) or adulthood (PND 132) increased bone mineral content (BMC) or bone strength in female rat offspring. Offspring were exposed to basal diet (BD) or one of two doses of SDG (50S, 100S) equivalent to that in a 50 or $100 \mathrm{~g}$ flaxseed/kg diet during lactation only or through to PND 50 or 132. At PND 50 and 132, femurs were analysed for BMC by dual energy X-ray absorptiometry and biomechanical strength by a 3-point bending test. Compared with BD group, rats exposed to continuous 50S or 100S diet had stronger femurs at PND 50 without changes in BMC. At PND 132 there were no differences in femur strength despite the fact that continuous exposure to BD resulted in a higher $(P<0 \cdot 05)$ $\mathrm{BMC}$ than rats exposed to $100 \mathrm{~S}$ during lactation only or to $50 \mathrm{~S}$ or $100 \mathrm{~S}$ during lactation through to adulthood. In conclusion, female rat bone is more sensitive to the oestrogen-like action of lignans during early life when endogenous levels of sex hormones are low, but by adulthood the improved bone strength does not persist. Importantly, exposure to purified lignan does not have negative effects on bone strength.
\end{abstract}

Lignan: Biomechanics: Bone mineral: Developing rats

The acquisition of peak bone mass is important to achieve optimal bone health and thereby reduce the risk of developing osteoporosis in later life (Eisman, 2000). The achievement of peak bone mass, starting in utero and continuing until the late teens or early twenties (Teegarden et al. 1995), is dependent on the complex interaction of hormones and growth factors, genetics, physical activity and nutrition, particularly $\mathrm{Ca}$ and vitamin D intakes (Slemenda et al. 1991, 1994; Johnston et al. 1992; Lonzer et al. 1996; Molgaard et al. 1999). Whether other specific food components such as phyto-oestrogens, possessing oestrogen or anti-oestrogen-like activity, make measurable contributions to the acquisition of peak bone mass is currently unclear. In addition to the acquisition of bone mass, the strength of the bone deposited is important to consider as bone strength is a predictor of fracture risk. Bone strength is influenced not only by bone mass, but also by the structural and material properties of bone (Weinstein, 2000). Whether or not phyto-oestrogens positively or negatively alter these properties of bone are uncertain.

Flaxseed (Linum usitatissimum) is the richest source of secoisolariciresinol diglycoside (SDG), the plant lignan precursor from which the two major mammalian lignans, enterolactone and enterodiol, are formed by the action of colonic bacteria (Thompson et al. 1991). Enterolactone and enterodiol are structurally similar to $17-\beta$-oestradiol and, consequently, have been shown to have both weak oestrogenic or anti-oestrogenic activity in both in vitro and in vivo studies depending on the dose, duration of administration and the stage of development (Tham et al. 1998; Thompson, 1998 Tou et al. 1998, 1999; Tou \& Thompson, 1999; Ward et al. 2000, 2001; Ward \& Thompson, 2001). The effect of exposure to dietary

\footnotetext{
Abbreviations: BD, basal diet; BMC, bone mineral content; PND, postnatal day; SDG, secoisolariciresinol diglycoside.

* Corresponding author: Dr Lilian U. Thompson, fax +1 416978 5882, email lilian.thompson@utoronto.ca
} 
components with oestrogen-like activity such as flaxseed and its purified lignan during early stages of the life-cycle on bone development in females has not been studied. In males, exposure to a diet containing lignan equivalent to the quantity present in a $100 \mathrm{~g}$ flaxseed/kg diet during either suckling only or through to early adulthood has no adverse effect on bone health as measures of bone mass and strength were similar to rats fed a diet devoid of phyto-oestrogens (Ward et al. 2001). Since oestrogen is a critical mediator of bone metabolism in females, flaxseed and its purified lignan (SDG) have the potential to modulate bone cell metabolism.

Studies reporting the effects of phyto-oestrogens on bone mass (for review, see Anderson \& Garner, 1998), in vivo, are limited to studies in which natural or synthetic isoflavones (i.e. ipriflavone) are administered to perimenopausal or postmenopausal women (Potter et al. 1998; Gennari, 1999; Alekel et al. 2000) or ovariectomized rats (Arjmandi et al. 1996, 1998; Fanti et al. 1998; Picherit et al. 2000) or mice (Ishimi et al. 1999, 2000). Administration of synthetic isoflavones to postmenopausal women has been shown to slow the loss of bone mineral at the radius, femur and/or spine after menopause (Gennari, 1999). Supplementation of isolated soyabean protein, containing isoflavones, has been reported to attenuate the loss of lumbar spine bone mineral content and density in perimenopausal (Alekel et al. 2000) and postmenopausal (Potter et al. 1998) women. In ovariectomized rats, administration of zearalanol and coumestrol, dietary oestrogens with structural similarities to 17- $\beta$-oestradiol, slowed bone loss after ovariectomy (Draper et al. 1997). Similarly, administering genistein attenuated trabecular and cortical bone loss associated with ovariectomy in rats (Arjmandi et al. 1996, 1998; Fanti et al. 1998; Picherit et al. 2000) or mice (Ishimi et al. 1999, 2000). Together, these studies provide evidence that phytooestrogens may assist in maintaining bone health and potentially stimulate the accretion of bone mass by exerting oestrogen-like effects on bone tissue, or by other mechanisms that have not yet been elucidated.

The overall objective of the present study was to evaluate in female rats if exposure to the purified lignan component from flaxseed during suckling via mother's milk or continuously during suckling through to adolescence (i.e. postnatal day (PND) 50) or adulthood (i.e. PND 132) would have a positive effect on bone development as indicated by a higher bone mineral content (BMC) accompanied by improved bone biomechanics (increased bone strength) compared with rats exposed only to basal diet (BD) that was devoid of phyto-oestrogens.

\section{Materials and methods}

\section{Diets}

The composition of the BD was based on the semi-purified AIN-93G diet (Reeves et al. 1993; Table 1). The BD was supplemented with 88.5 or $177.2 \mathrm{mg}$ purified SDG/kg, equivalent to the level of SDG present in a diet containing $50(50 \mathrm{~S})$ or $100(100 \mathrm{~S}) \mathrm{g}$ flaxseed $/ \mathrm{kg}$ diet respectively (Table 1). These levels of lignans in flaxseed were chosen because previous investigation in our laboratory demonstrated that hormonal effects on oestrogen-sensitive tissues
Table 1. Composition of the basal diet $(\mathrm{BD})^{*}$ and diets supplemented with secoisolariciresinol diglycoside $(50 \mathrm{~S}, 100 \mathrm{~S})(\mathrm{g} / \mathrm{kg})$

\begin{tabular}{lccc}
\hline Ingredient $\dagger$ & $\begin{array}{c}\mathrm{BD} \\
(\mathrm{g} / \mathrm{kg})\end{array}$ & $\begin{array}{c}50 \mathrm{~S} \text { diet } \\
(\mathrm{g} / \mathrm{kg})\end{array}$ & $\begin{array}{c}100 S \text { diet } \\
(\mathrm{g} / \mathrm{kg})\end{array}$ \\
\hline Cornstarch & 397.48 & 397.39 & 397.30 \\
Casein & 200 & 200 & 200 \\
Soyabean oil & 70.02 & 70.02 & 70.02 \\
Dextrose & 132 & 132 & 132 \\
Sucrose & 100 & 100 & 100 \\
Cellulose & 50 & 50 & 50 \\
AIN-93G mineral mix $\neq$ & 35 & 35 & 35 \\
AIN-93G vitamin mix§ & 10 & 10 & 10 \\
L-Cystine & 3 & 3 & 3 \\
Choline bitartrate & 2.5 & 2.5 & 2.5 \\
SDG\|l & 0 & 0.09 & 0.18 \\
\hline
\end{tabular}

SDG, secoisolariciresinol diglycoside.

${ }^{*}$ Based on AIN-93G diet (Reeves et al. 1993).

†All ingredients, except SDG, were supplied by Dyets Inc., Bethleham, PA, USA.

$\ddagger$ Contained $(\mathrm{g} / \mathrm{kg})$ : calcium carbonate 357 , potassium phosphate (monobasic) 196 , potassium citrate $70 \cdot 78$, sodium chloride 74 , potassium sulfate $46 \cdot 6$, magnesium oxide 24 , ferric citrate $6 \cdot 06$, zinc carbonate $1 \cdot 65$, manganous carbonate 0.63 , cupric carbonate 0.3 , potassium iodate 0.01 , sodium selenate 0.01025 , ammonium paramolybdate 0.00795 , sodium metasilicate 1.45 , chromium potassium sulfate 0.275 , lithium chloride 0.0174 , boric acid 0.0815 , sodium fluoride 0.0635 , nickel carbonate 0.0318 , ammonium vanadate 0.0066, sucrose (finely powdered) 221.026.

$\S$ Contained $(\mathrm{g} / \mathrm{kg})$ : niacin 3 , calcium pantothenate 1.6 , pyridoxine hydrochloride 0.7 , thiamine hydrochloride 0.6 , riboflavin 0.6 , folic acid 0.2 , biotin $0.02, \alpha$-tocopherol acetate 15 , cyanocobalamin $(1 \mu \mathrm{g} / \mathrm{g}) 2 \cdot 5$, retinyl palmitate 0.8 , cholecalciferol 0.25 , phylloquinone-dextrose $(10 \mathrm{mg} / \mathrm{g}) \quad 7.5$, sucrose $967 \cdot 23$.

\|The quantity of SDG added to the $50 \mathrm{~S}$ and $100 \mathrm{~S}$ diets was based on a SDG concentration of $2.93 \mu \mathrm{mol}$ SDG/g flaxseed by HPLC analysis (Thompson et al. 1996).

are observed at these levels (Tou et al. 1998; Tou \& Thompson, 1999; Ward et al. 2000). Diets were stored at $4{ }^{\circ} \mathrm{C}$. Fresh diet was provided to rats every $2-3 \mathrm{~d}$ at which time food that remained in the food jar was weighed and recorded in order to monitor total food intake, and specifically the intake of SDG.

\section{Experimental design}

Twenty timed pregnant rats were obtained on day 2 of gestation at 8 weeks of age (Sprague-Dawley; Charles River Canada, Montreal, Que., Canada) and were fed the BD for the duration of their pregnancy. All rats delivered between day 21 and 22 of pregnancy. At the time of delivery, dams were randomized to one of three diets: $\mathrm{BD}$ ( $n 4$ dams), $50 \mathrm{~S}$ ( $n 8$ dams) or 100S ( $n 8$ dams). No pups were culled from any litter as there were no significant differences in the total number of offspring (mean value 10-12 pups per litter) or the number of males and females per litter. The present study reports the findings from the female offspring as the findings for the male offspring have been previously reported (Ward et al. 2001). Dams were allowed free access to distilled water and their assigned diet throughout pregnancy and lactation. It has been shown that feeding diets containing purified SDG to lactating dams results in the transfer of lignan to their offspring (Tou et al. 1998). At PND 21 (end of lactation), offspring were weaned, housed in pairs and either continued on their mother's diet or were switched to BD until PND 50 or 132. All offspring were provided free access to distilled water and their respective 
diets throughout the study. Offspring from dams randomized to BD during lactation remained on BD until PND 50 or 132. Thus, a proportion of offspring were exposed to purified SDG during suckling only, while the other proportion were continuously exposed to purified SDG from the start of suckling through to necropsy at PND 50 or 132. From PND 2 through PND 50 or 132, body weight was measured once per week. Food intake was monitored throughout the study and SDG intakes were estimated from the food intakes. Rats were killed by $\mathrm{CO}_{2}$ inhalation followed by cervical dislocation at either PND 50 or 132 .

This experimental protocol was approved by the Animal Care Committee at the University of Toronto, Canada. All animal care and procedures were conducted in accordance with the Guide to the Care and Use of Experimental Animals (Canadian Council on Animal Care, 1984).

\section{Urinary lignans}

Urine samples for lignan analysis were collected into glass jars containing preservative ( $1 \mathrm{mg}$ ascorbic acid) over a $3 \mathrm{~d}$ period in the week prior to necropsy at PND 50 or 132. Urine was analysed for total lignans (enterodiol + enterolactone + secoisolariciresinol (the aglycone of SDG)) by GC-mass spectrometry (Hewlett-Packard 5890 Series II; Hewlett-Packard, Mississauga, Ont., Canada) as previously detailed by Rickard et al. (1996). Urinary lignan values are expressed as the average daily excretion over the $3 \mathrm{~d}$ urine collection.

\section{Femur measurements}

At necropsy, femurs were excised and cleaned of soft tissue. Prior to conducting dual-energy X-ray absorptiometry or biomechanical strength testing, femur weight and length and width at the midpoint (in two directions, referred to as width 1 and width 2) were measured using a digital scale or calipers. Femur width was measured in two directions, because rat femurs are not circular at the midpoint.

\section{Femur area and bone mineral content using dual-energy $X$-ray absorptiometry}

Femur area and BMC were assessed by dual-energy X-ray absorptiometry (Hologic QDR ${ }^{\circ}$ 4500; Hologic Inc., Waltham, MA, USA) using the small animal high resolution software (version 8.23). To mimic soft tissue, excised femurs were submerged in $2.5 \mathrm{~cm}$ water in a plastic, thinwalled container $(10 \mathrm{~cm}$ wide $\times 15 \mathrm{~cm}$ long $)$ with a smooth, uniform surface during scans (Ward et al. 2001).

\section{Biomechanical strength testing}

Bone biomechanical strength variables were assessed using a TA.XT2i Texture analyser (Texture Technologies, Scarsdale, NY, USA) in 3-point bending as previously described (Ward et al. 2001). Briefly, femurs were placed on supports (1 mm width at tip) and were bent until broken by lowering a centrally placed blade ( $1 \mathrm{~mm}$ width) at a constant crosshead speed $(0 \cdot 1 \mathrm{~mm} / \mathrm{s})$. The load-deflection data were collected by an IBM-compatible personal computer interfaced with the TA.XT2i. Sample test distance was set at $10.0 \mathrm{~mm}$ with a signal collection rate of 100 points/s. Several whole bone properties were determined: (1) bioyield expressed in $\mathrm{N}$, defined as the force at which the first damage to the bone tissue occurs, indicated by a break in the initial slope; (2) peak force $(\mathrm{N})$ defined as the maximum force obtained during the bending procedure indicated by the highest point after which the bone breaks and the force reading drops to zero; (3) bending failure energy ( $\mathrm{J}$ ) defined as the work energy (area under the curve) required to break the bone in bending; and (4) ultimate stiffness $(\mathrm{N} / \mathrm{mm})$ defined as the tangent of the linear region of the load-deflection curve to the $x$-axis (Ørtoft \& Oxlund, 1988). From these data, several calculated values were derived to take into account bone size (diameter): (1) ultimate bending stress (UBS; N/mm²) calculated as:

$$
\mathrm{UBS}=\frac{8 \times \text { peak force } \times L \times \mathrm{a}_{1}}{\pi \times\left(\mathrm{a}_{1}^{3} \times \mathrm{a}_{2}-\mathrm{b}_{1}^{3} \times \mathrm{b}_{2}\right)},
$$

where $L$ is the distance between the supports $(13 \mathrm{~mm}$ for $132 \mathrm{~d}$ females, $10 \mathrm{~mm}$ for $50 \mathrm{~d}$ females), $\mathrm{a}_{1}$ is the outer diameter of the bone parallel to the central blade and supports, $\mathrm{a}_{2}$ is the outer diameter of the bone perpendicular (or normal) to the blade and supports, $b_{1}$ is the inner diameter of the bone at $\mathrm{a}_{1}$ and $\mathrm{b}_{2}$ is the inner diameter at $\mathrm{a}_{2}$; and (2) Young's modulus $\left(\mathrm{N} / \mathrm{mm}^{2}\right)$ calculated as:

$$
\text { Young's modulus }=\frac{4 \times L^{3} \times \text { ultimate stiffness }}{3 \times \pi \times\left(\mathrm{a}_{1}^{3} \times \mathrm{a}_{2}-\mathrm{b}_{1}^{3} \times \mathrm{b}_{2}\right)},
$$

where $L, \mathrm{a}_{1}, \mathrm{a}_{2}, \mathrm{~b}_{1}$ and $\mathrm{b}_{2}$ are defined as earlier (Ørtoft et al. 1992; Oxlund et al. 1995).

\section{Statistical analyses}

Statistical analyses were performed using SigmaStat software (version 2.0; Jandel Scientific, San Rafael, CA, USA). For data that was normally distributed, a one-way ANOVA followed by Tukey's test was used to determine differences among treatment groups. For data that did not follow a normal distribution, a Kruskal-Wallis one-way ANOVA on ranks followed by Dunn's test was used to detect differences among groups. Differences with $P \leq$ $0 \cdot 05$ were considered significant. All data are expressed as the mean values with their standard errors except data presented in Table 3 which are expressed as the median values (25th percentile, 75 th percentile) as these data did not follow a normal distribution.

\section{Results \\ Food intake and weight growth}

From the end of lactation through to PND 50 or PND 132, there were no differences in the mean food intake/d among treatment groups. Mean food intake from PND 21 through PND 50 was 14.5 (SEM 0.3) g/d and through to PND 132 was $15 \cdot 2$ (SEM 0.4) g/d. By design, SDG intakes were lower $(P<0 \cdot 05)$ among rats receiving the continuous 50S $(2 \cdot 2$ (SEM $0 \cdot 1) \mu \mathrm{mol} \mathrm{SDG} / \mathrm{d}$ ) than those receiving continuous 100S $(4 \cdot 3($ SEM 0.1) $\mu$ mol SDG/d) diet and both are lower 
$(P<0.05)$ compared with rats receiving $\mathrm{BD}$ (devoid of SDG). There were no significant differences in body weight at either PND 50 (mean 202 (SEM 8) g) or PND 132 (355 (SEM 11) g) among treatment groups.

\section{Urinary lignans}

The mean total urinary lignan excretion (enterodiol + enterolactone + secoisolariciresinol) of rats consuming the continuous $50 \mathrm{~S}$ and $100 \mathrm{~S}$ diets was greater $(P<0 \cdot 001)$ than rats receiving $\mathrm{BD}$ at $\mathrm{PND} 50$ (Fig. 1). In addition, rats exposed to the continuous $100 \mathrm{~S}$ diet had higher $(P<0.05)$ lignan excretion than the 50S diet group. At PND 132, these differences among treatment groups persisted (results not shown).

\section{Femur size}

At PND 50, femur weights (645 (SEM 8) mg) and lengths $(28.7$ (SEM 0.2) $\mathrm{mm}$ ) were not different among groups exposed to BD, $50 \mathrm{~S}$ or $100 \mathrm{~S}$ diet. The width at the midshaft (width 1) of rats continuously exposed to $100 \mathrm{~S}$ diet $(2 \cdot 81$ (SEM 0.05$) \mathrm{mm}$ ) was smaller $(P=0.030)$ than the BD group (3.00 (SEM 0.04) mm). The other width (width 2) was not significantly different among groups but a similar trend was present. The average of these two widths of rats continuously exposed to $50 \mathrm{~S}$ and $100 \mathrm{~S}$ diet were smaller $(P=0.036)$ compared with BD group. By PND 132, the femurs of rats exposed to $50 \mathrm{~S}$ continuously from lactation through PND 132 were lighter $(P=0 \cdot 036)$ than the femurs of rats continuously exposed to BD. Femur length $(34 \cdot 2$

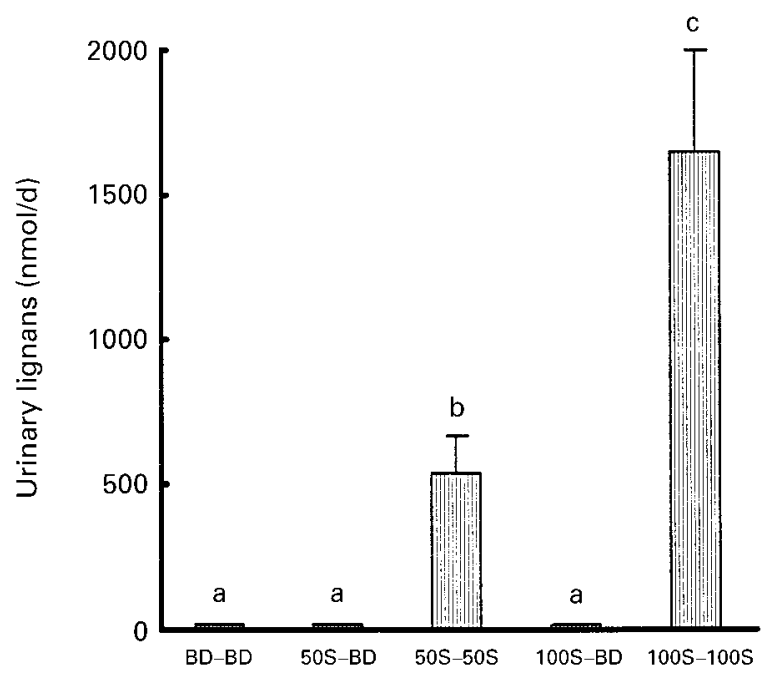

Fig. 1. Effect of dietary lignans on total urinary lignan excretion (enterodiol, enterolactone and secoisolariciresinol (the aglycone of secoisolariciresinol diglycoside)) at postnatal day (PND) 50 in rats. For details of diets and procedures, see Table 1 and p. 500. Values are means with their standard errors represented by vertical bars. $\mathrm{BD}-\mathrm{BD}$, rats received basal diet during lactation through to PND 50 ; 50S-BD, $100 S-B D$, rats received the respective lignan-containing diet during lactation but from the end of lactation through to PND 50, they received basal diet; 50S-50S, 100S-100S, rats received the respective lignan-containing diet during lactation through to PND 50. ${ }^{a, b, c}$ Mean values with unlike superscript letters were significantly different $(P<0.001)$.
(SEM 0.3) $\mathrm{mm}$ ) and width at midshaft (width 13.99 (SEM $0 \cdot 04$ ) mm, width $23 \cdot 15$ (SEM 0.03) $\mathrm{mm}$ ) were not different among any group.

\section{Femur area and bone mineral content}

At PND 50, there were no differences in femur area or BMC among groups but significant differences were observed when rats reached adulthood at PND 132 (Table 2). At PND 132, femur area was reduced $(P=0 \cdot 024)$ among rats continuously exposed to $50 \mathrm{~S}$ and $100 \mathrm{~S}$ diet compared with the BD group (Table 2). Exposure to $100 \mathrm{~S}$ diet during suckling only and continuous exposure to 50S and 100S diet resulted in a lower $(P=0.006)$ BMC than the BD group (Table 2).

\section{Biomechanical strength testing}

At PND 50, the bioyield (25 (SEM 0.1) N), peak force (65 (SEM 1) N), ultimate stiffness (124 (SEM 2) N/mm) and bending failure energy (47 (SEM 2) J) did not differ significantly among treatment groups. However, significant differences in femur strength and stiffness were observed when peak force and ultimate stiffness were normalized for differences in the dimensions of the femur at the midpoint. Ultimate bending stress was higher $(P=0 \cdot 005)$ among rats continuously exposed to $100 \mathrm{~S}$ diet compared with the BD group (Table 3 ). In addition, rats continuously exposed to $50 \mathrm{~S}$ or $100 \mathrm{~S}$ diet had a higher $(P=0.021)$ Young's modulus than the rats exposed to BD (Table 3). In contrast, at PND 132, there were no differences in the bioyield (107 (SEM 2) N), peak force (157 (SEM 2) N), ultimate stiffness (190 (SEM 2) N/mm), bending failure energy (122 (SEM 4) $\mathrm{J})$, or the normalized biomechanical measurements such as ultimate bending stress (156 (SEM 4) N/mm ${ }^{2}$ ) or Young's modulus (1707 (SEM 61) N/mm ${ }^{2}$ ) among groups.

\section{Discussion}

The present study is the first to report the effect of purified lignan from flaxseed on the acquisition of bone mass and, perhaps more importantly, the quality of bone (i.e. biomechanical strength) deposited at specific stages of the life cycle such as adolescence and early adulthood. We have demonstrated that the lignan in flaxseed can alter bone development as continuous exposure to the purified lignan at the level present in a $100 \mathrm{~g}$ flaxseed $/ \mathrm{kg}$ diet resulted in increased bone strength compared with the BD group at PND 50. While these changes are small and not sustained into adulthood, the fact that exposure to both the continuous $50 \mathrm{~S}$ and 100S diet resulted in a similar elevation in bone strength at PND 50, suggests that the lower dose of lignan is sufficient to observe these modest changes in bone development. Other investigators have also reported a lack of a dose-response effect with another phyto-oestrogen, genistein, on bone metabolism. Anderson et al. (1998) reported that the most effective dose of genistein at preserving bone mass was $0.5 \mathrm{mg} / \mathrm{kg}$ body weight per $\mathrm{d}$ while higher doses $(1.6$ and $5.0 \mathrm{mg} / \mathrm{d})$ did not preserve bone mass in the ovariectomized lactating rat model of osteoporosis. 
Table 2. Femur area and bone mineral content (BMC) of female rats fed on a basal diet (BD) or diets supplemented with secoisolariciresinol diglycoside (50S, 100S) at postnatal day 50 and $132^{*}$

(Mean values with their standard errors)

\begin{tabular}{|c|c|c|c|c|c|c|c|c|c|c|}
\hline \multirow[b]{2}{*}{ Treatment† } & \multicolumn{5}{|c|}{ Postnatal day 50} & \multicolumn{5}{|c|}{ Postnatal day 132} \\
\hline & $n$ & Bone area $\left(\mathrm{cm}^{2}\right)$ & SEM & $\mathrm{BMC}(\mathrm{mg})$ & SEM & $n$ & Bone area $\left(\mathrm{cm}^{2}\right)$ & SEM & $\mathrm{BMC}(\mathrm{mg})$ & SEM \\
\hline $\mathrm{BD}-\mathrm{BD}$ & 8 & 1.25 & 0.02 & 183 & 4 & 7 & $1.92^{\mathrm{a}}$ & 0.02 & $456^{\mathrm{a}}$ & 10 \\
\hline $50 S-B D$ & 10 & $1 \cdot 22$ & 0.03 & 171 & 5 & 7 & $1.83^{a b}$ & 0.03 & $411^{\mathrm{ab}}$ & 10 \\
\hline $50 S-50 S$ & 8 & 1.23 & 0.03 & 184 & 7 & 10 & $1.77^{\mathrm{b}}$ & 0.03 & $401^{\mathrm{b}}$ & 10 \\
\hline $100 S-B D$ & 9 & $1 \cdot 21$ & 0.02 & 177 & 3 & 9 & $1.80^{\mathrm{ab}}$ & 0.04 & $403^{\mathrm{b}}$ & 9 \\
\hline $100 S-100 S$ & 11 & $1 \cdot 20$ & 0.02 & 170 & 6 & 8 & $1 \cdot 78^{\mathrm{b}}$ & 0.04 & $409^{b}$ & 13 \\
\hline
\end{tabular}

a,b Mean values within a column with unlike superscript letters were significantly different $(P<0.05)$.

* For details of diets and procedures, see Table 1 and p. 500.

†BD-BD, rats received basal diet during lactation through to PND 50 or $132 ; 50 S-B D, 100 S-B D$, rats received the respective lignan-containing diet during lactation but from the end of lactation through to PND 50 or 132 they received BD; 50S-50S, 100S-100S, rats received the respective lignan-containing diet during lactation through to PND 50 or 132.

It is biologically plausible that the lignan exerted a hormone-like action as it has recently been reported that mRNA for oestrogen receptor- $\beta$ has ligand specificity toward phyto-oestrogens (Kuiper et al. 1997), and is expressed in osteoblasts covering the metaphyseal trabecular surface of the femurs of 21-d-old female rats (Windahl et al. 2000). Since rats are expressing mRNA for oestrogen receptor- $\beta$ at the end of the suckling period (PND 21), and possibly earlier, exposure to lignans during suckling may potentially exert direct effects on bone tissue via interaction with the oestrogen receptor- $\beta$.

The fact that bone strength was greater without elevations in BMC at PND 50 suggests that it is the deposition of organic matrix, including bone specific proteins such as type 1 collagen, as well as the organization of this organic matrix (i.e. cross-linking of collagen) that contributed to the greater bone strength among these rats exposed to continuous 50S or $100 \mathrm{~S}$ diet. Administration of $\beta$-amino-propionitrile, an irreversible inhibitor of the enzyme lysyl oxidase that is essential for the formation of collagen cross-links, has been shown to dramatically reduce the strength of bone without altering the mineral content of bone in 70-d-old female rats (Oxlund et al. 1995). Thus, in addition to the quantity of matrix deposited, the modelling and formation of collagen cross-links is essential to develop bones that are less susceptible to fractures. Moreover, a recent study in growing pigs exposed to differing ratios of dietary $n-6$ and $n-3$ fatty acids reported that although differences in bone strength were observed, total BMC and bone mineral density as well as \% bone ash did not differ among the same groups (Johanson et al. 2000). This finding, combined with the findings from the present study, provide further evidence that bone strength is at least somewhat independent of the quantity of bone mineral.

To date, no studies have specifically investigated the effect of lignans on the deposition of bone matrix proteins or cross-linking of collagen but there is information that ipriflavone, a synthetic isoflavone, stimulates the mRNA expression of bone-specific proteins (type 1 collagen, osteopontin, bone specific protein) (Cheung et al. 1994). Moreover, oestrogen has direct effects on cell growth and the differentiated functions of osteoblasts, resulting in the production or inhibition of the expression of numerous matrix proteins as well as growth factors (insulin-like growth factor-I, transforming growth factor- $\beta$ ), cytokines (interleukin $1 \alpha, 1 \beta$ and 6 ; tumour necrosis factor $\alpha$ ), and parathyroid hormone and 1,25-dihydroxycholecalciferol receptors involved in bone remodelling (Harris et al. 1996). The effects of lignan on the proliferation and differentiation of osteoblasts, or its effects on the osteoclasts remain to be elucidated.

Since the improved bone strength among rats exposed to

Table 3. Selected biomechanical strength measurements of femurs from female rats fed on a basal diet (BD) or diets supplemented with secoisolariciresinol diglycoside $(50 \mathrm{~S}, 100 \mathrm{~S})$ at postnatal day $50^{*}$

(Median values and 25th and 75th percentiles)

\begin{tabular}{|c|c|c|c|c|c|c|c|}
\hline \multirow[b]{2}{*}{ Treatment† } & \multirow[b]{2}{*}{$n$} & \multicolumn{3}{|c|}{$\begin{array}{l}\text { Ultimate bending stress } \\
\qquad\left(\mathrm{N} / \mathrm{mm}^{2}\right)\end{array}$} & \multicolumn{3}{|c|}{$\begin{array}{l}\text { Young's modulus } \\
\left(\mathrm{N} / \mathrm{mm}^{2}\right)\end{array}$} \\
\hline & & Median & 25th percentile & 75th percentile & Median & 25th percentile & 75th percentile \\
\hline BD-BD & 8 & $54^{\mathrm{a}}$ & 47 & 63 & $580^{a}$ & 495 & 700 \\
\hline $50 S-B D$ & 10 & $59^{\mathrm{ab}}$ & 58 & 61 & $666^{\mathrm{ab}}$ & 640 & 817 \\
\hline $50 S-50 S$ & 9 & $73^{b}$ & 67 & 76 & $808^{\mathrm{ab}}$ & 689 & 884 \\
\hline $100 S-B D$ & 9 & $67^{\mathrm{ab}}$ & 63 & 76 & $714^{\mathrm{ab}}$ & 647 & 802 \\
\hline $100 S-100 S$ & 10 & $71^{\mathrm{b}}$ & 67 & 72 & $826^{b}$ & 679 & 936 \\
\hline
\end{tabular}

${ }^{\mathrm{a}, \mathrm{b}}$ Mean values within a column with unlike superscript letters were significantly different $(P=0.005)$.

${ }^{*}$ For details of diets and procedures, see Table 1 and p. 500.

†BD-BD, rats received basal diet during lactation through to PND 50; 50S-BD and 100S-BD, rats received the respective lignan-containing diet during lactation but from the end of lactation through to PND 50 they received BD; 50S-50S, 100S-100S, rats received the respective lignan-containing diet during lactation through to PND 50. 
100S from the start of lactation through to PND 50 was not maintained by PND 132, it appears that the early, modest benefit does not have a sustained effect. It is possible that the elevation in endogenous steroid hormones (oestrogen, progesterone) after PND 50 and through to adulthood, overrides the positive, potential oestrogen-like effects of exposure to lignans. The production and circulating concentrations of sex steroid hormones dramatically rises at the time of puberty onset, and therefore by PND 50, rats would have only experienced minimal exposure to the rising endogenous oestrogen levels. Thus, dietary phyto-oestrogens can accelerate bone development during early life when endogenous levels of sex hormones, particularly oestrogen, are relatively low.

The reason why bone area and BMC at PND 132 were reduced in all groups exposed to purified lignan compared with BD is not clear. Although BMC was not significantly different among groups at PND 50 there were differences among groups, e.g. $8 \%$ for continuous $100 \mathrm{~S}$ group $v$. BD group, and this difference significantly increased to $14 \%$ by PND 132. The fact that the difference in bone area also increased from $4 \%$ at PND 50 to $8 \%$ at PND 132 indicates that bone size was similarly reduced by the purified lignan. To our knowledge, the effect of exogenous oestrogen in young, healthy, growing rats has not been described. One study has reported that continuous subcutaneous infusion of 17 - $\beta$-oestradiol to 3 -month-old rats post-ovariectomy did not increase bone formation. Moreover, the steady state mRNA levels for bone matrix proteins and mineral apposition rate were unchanged or reduced with oestrogen treatment (Westerlund et al. 1993). Since lignans are considered 'weak oestrogens', possessing approximately $0 \cdot 01-0 \cdot 001$ of the oestrogen-like activity of 17- $\beta$ oestradiol, and that the dose of 17 - $\beta$-oestradiol used by Westerlund et al. (1993) was unphysiological (0.5 mg/d), the mechanism of lignan action on bone area and $\mathrm{BMC}$ requires further investigation. Interestingly, the difference in BMC did not translate into a weakening of bone structure, and, as discussed earlier, this may be because bone strength is dependent on both the quantity of bone mineral as well as the quality of bone matrix and the ultrastructure of the bone architecture.

In conclusion, exposure to dietary lignans does result in stronger bones at adolescence. While the overall effects of continuous exposure to dietary lignans on the acquisition of bone mass and bone strength beyond PND 50 through to young adulthood do not persist, it is reassuring that exposure to lignans, at the level present in a $100 \mathrm{~S}$ diet do not have negative effects on bone strength as has been previously reported among male rats under the same experimental conditions (Ward et al. 2001). However, the long-term consequences of the reduced bone area and BMC observed among rats exposed to lignans at PND 132 in the present study require further investigation. Exposure to dietary oestrogens may be of greater benefit when endogenous oestrogen levels are low as accompanies the ageing process or in specific disease states.

\section{Acknowledgements}

The authors thank P. Mascarin and F. Cheung for their technical assistance with the dual-energy X-ray absorptiometry and lignan analyses respectively. This research was supported by a grant from the Natural Sciences and Engineering Research Council of Canada, and a postdoctoral fellowship to W. Ward from the National Institute of Nutrition, Canada.

\section{References}

Alekel DL, St. Germain A, Peterson CT, Hanson KB, Stewart JW \& Toshiya T (2000) Isoflavone-rich soy protein isolate attenuates bone loss in the lumbar spine of perimenopausal women. American Journal of Clinical Nutrition 72, 844-852.

Anderson JJ, Ambrose WW \& Garner SC (1998) Biphasic effects of genistein on bone tissue in the ovariectomized lactating rat model. Proceedings of the Society for Experimental Biology and Medicine 217, 345-350.

Anderson JJ \& Garner SC (1998) Phytoestrogens and bone. Baillieres Clinics in Endocrinology and Metabolism 12, 543-557.

Arjmandi BH, Alekel L, Hollis BW, Amin D, StacewiczSapuntzakis M, Guo P \& Kukreja SC (1996) Dietary soybean protein prevents bone loss in an ovariectomized rat model of osteoporosis. Journal of Nutrition 126, 161-167.

Arjmandi BH, Birnbaum R, Goyal NV, Getlinger MJ, Juma S, Alekel L, Hasler CM, Drum ML, Hollis BW \& Kukreja SC (1998) Bone-sparing effect of soy protein in ovarian hormonedeficient rats is related to its isoflavone content. American Journal of Clinical Nutrition 68, Suppl., 1364S-1368S.

Canadian Council on Animal Care (1984) Guide to the Care and Use of Experimental Animals, Ottawa, Ont.: Institute of Laboratory Animal Resources Commission on Life Sciences.

Cheung SL, Zhang SF, Nelson TL, Warlow PM \& Civitelli R (1994) Stimulation of human osteoblast differentiation and function by ipriflavone and its metabolites. Calcified Tissue International 55, 356-362.

Draper CR, Edel MJ, Dick IM, Randall AG, Martin GB \& Prince RL (1997) Phytoestrogens reduce bone loss and bone resorption in oophorectomized rats. Journal of Nutrition 127, 1795-1799.

Eisman JA (2000) Genetics of osteoporosis. Endocrine Reviews 20, 788-804.

Fanti P, Monier-Faugere MC, Geng Z, Schmidt J, Morris PE, Cohen D \& Malluche HH (1998) The phytoestrogen genistein reduces bone loss in short-term ovariectomized rats. Osteoporosis International 8, 274-281.

Gennari C (1999) Calcitonin, bone-active isoflavones and vitamin D metabolites. Osteoporosis International 2, S81-S90.

Harris SA, Tau KR, Turner RT \& Spelsberg TC (1996) Estrogens and progestins. In Principles of Bone Biology, pp. 510-513 [JP Bilezikian, LG Raisz and GA Rodan, editors]. San Diego, CA: Academic Press.

Ishimi Y, Arai N, Wang X, Wu J, Umegaki K, Miyaura C, Takeda A \& Ikegami S (2000) Difference in effective dosage of genistein on bone and uterus in ovariectomized mice. Biochemical and Biophysical Research Communications 274, 697-701.

Ishimi Y, Miyaura C, Ohmura M, Onoe Y, Sata H, Uchiyama Y, Ito M, Wang X, Suda T \& Ikegama S (1999) Selective effects of genistein, a soybean isoflavone, on B-lymphopoiesis and bone loss caused by estrogen deficiency. Endocrinology 140, $1893-1900$

Johanson JC, Crenshaw TD \& Benvenuga NJ (2000) Bone strength is compromised by dietary $(n-6)$ fatty acids independent of bone ash and bone mineral density in newborn pigs. FASEB Journal 14, A38.

Johnston CJ, Miller JZ, Slemenda CW, Reister TK, Hui S, 
Christian JC \& Peacock M (1992) Calcium supplementation and increases in bone mineral density in children. New England Journal of Medicine 327, 82-87.

Kuiper GGJM, Carlsson B, Grandien K, Enmark E, Haggblad J, Nilsson S \& Gustaffson J-A (1997) Comparison of the ligand binding specificity and transcript tissue distribution of estrogen receptors alpha and beta. Endocrinology 138, 863-870.

Lonzer MD, Imrie R, Rogers D, Worley D, Licata A \& Secic M (1996) Effects of heredity, age, weight, puberty, activity, and calcium intake on bone mineral density in children. Clinical Pediatrics 35, 185-189.

Molgaard C, Thomsen BT \& Michaelsen KF (1999) Whole body bone mineral accretion in healthy children and adults. Archives of Diseases in Childhood 81, 10-15.

Ørtoft G \& Oxlund H (1988) Reduced strength of rat cortical bone after glucocorticoid treatment. Calcified Tissue International 43, $376-382$

Ørtoft G, Oxlund H, Jorgensen PH \& Andreassen TT (1992) Glucocorticoid treatment of food deprivation counteract the stimulating effect of growth hormone on rat cortical bone strength. Acta Paediatrica 81, 912-917.

Oxlund H, Barckman M, Ørtoft G \& Andreassen TT (1995) Reduced concentrations of collagen cross-links are associated with reduced strength of bone. Bone 17, 365S-371S.

Picherit C, Coxam V, Bennetau-Pelissero C, Kati-Coulibaly S, Davicco MJ, Lebecque P \& Barlet JP (2000) Daidzein is more efficient than genistein in preventing ovariectomy-induced bone loss in rats. Journal of Nutrition 130, 1675-1681.

Potter SM, Baum J-A, Teng H, Stillman RJ, Shay NF \& Erdman JW Jr (1998) Soy protein and isoflavones: their effects on blood lipids and bone density in postmenopausal women. American Journal of Clinical Nutrition 68, Suppl., 1375S-1379S.

Reeves PG, Nielsen FM \& Fahey GC Jr (1993) AIN-93 purified diets for laboratory rodents: final report of the American Institute of Nutrition ad hoc writing committee on the reformulation of the AIN-76A rodent diet. Journal of Nutrition 123, 1939-1951.

Rickard SE, Orcheson LJ, Seidl MM, Luyengi L, Fong HHS \& Thompson LU (1996) Dose-dependent production of mammalian lignans in rats and in vitro from the purified precursor secoisolariciresinol diglycoside in flaxseed. Journal of Nutrition 126, 2012-2019.

Slemenda CW, Miller MZ, Hui SL, Reister TK \& Johnston CC Jr (1991) Role of physical activity in the development of skeletal mass in children. Journal of Bone and Mineral Research 6 , 1227-1233.

Slemenda CW, Reister TK, Hui SL, Miller JZ, Christian JC \& Johnston CC Jr (1994) Influences on skeletal mineralization in children and adolescents. Journal of Pediatrics 125, 201-207.
Teegarden D, Proulx WR, Martin BR, Zhao J, McCabe GP, Lyle RM, Peacock M, Slemenda C, Johnston CC \& Weaver CM (1995) Peak bone mass in young women. Journal of Bone Mineral Research 10, 711-715.

Tham DM, Gardner CD \& Haskell WL (1998) Potential health benefits of dietary phytoestrogens: a review of the clinical, epidemiological, and mechanistic evidence. Journal of Clinical Endocrinology and Metabolism 83, 2223-2235.

Thompson LU, Rickard SE, Orcheson LJ \& Seidel MM (1996) Flaxseed and its lignan components reduce mammary tumor growth at a late stage of carcinogenesis. Carcinogenesis 17, $1373-1376$.

Thompson LU, Robb P, Serraino M \& Cheung F (1991) Mammalian lignan production from various foods. Nutrition and Cancer 16, 43-52.

Thompson LU (1998) Experimental studies on lignans and cancer. Baillieres Clinics in Endocrinology and Metabolism 12, 691-705.

Tou JCL, Chen J \& Thompson LU (1998) Flaxseed and its lignan precursor secoisolariciresinol diglycoside affects pregnancy outcome and reproductive development in rats. Journal of Nutrition 128, 1861-1868.

Tou JCL, Chen J \& Thompson LU (1999) Dose, timing and duration of flaxseed exposure affect reproductive indices and sex hormone levels in rats. Journal of Toxicology and Environmental Health 56, 555-570.

Tou JCL \& Thompson LU (1999) Exposure to flaxseed or its lignan component during different developmental stages influences rat mammary gland structures. Carcinogenesis 20, $1831-1835$.

Ward WE, Jiang FO \& Thompson LU (2000) Exposure to flaxseed or purified lignan during lactation influences rat mammary gland structures. Nutrition and Cancer 37, 69-74.

Ward WE \& Thompson LU (2001) Dietary estrogens of plant and fungal origin: occurrence and exposure. In Handbook of Environmental Chemistry, [M Metzler, editor]. Heidelberg: Springer-Verlag (In the Press).

Ward WE, Yuan YV, Cheung AM \& Thompson LU (2001) Exposure to flaxseed and its purified lignan reduces bone strength in young but not older male rats. Journal of Toxicology and Environmental Health 63, 53-65.

Weinstein RS (2000) True strength. Journal of Bone and Mineral Research 15, 621-625.

Westerlund KC, Wakley GK, Evans GL \& Turner RT (1993) Estrogen does not increase bone formation in growing rats. Endocrinology 133, 2924-2934.

Windahl SH, Norgard M, Kuiper GGJM, Gustafsson J-A \& Andersson G (2000) Cellular distribution of estrogen receptor $\beta$ in neonatal rat bone. Bone 26, 117-121. 